\title{
Biologia, conhecimento e consciência: articulações possíveis na construção da aprendizagem
}

\author{
Biology, knowledge and consciousness: possible links in learning construction
}

\author{
Biología, conocimiento y conciencia: posibles conexiones en la \\ construcción del aprendizaje
}

\author{
PÂMELA ZiLiotTo SANT'ANNA FLACH* \\ FERNANDO BECKER**
}

\begin{abstract}
$\diamond$
RESUMO

Neste trabalho apresenta-se uma discussão acerca das contribuições da neurobiologia e da epistemologia genética aos processos de construção do conhecimento e da consciência. Discute-se, também, como tais processos se relacionam com os mecanismos de conservação da homeostase dos organismos. Para isso, debruçou-se sobre obras de António Damásio e Jean Piaget na tentativa de compreender as articulações entre organismo e sujeito epistêmico como protagonistas dos atos de manter-se vivo, conhecer e tomar consciência. Seja no âmbito orgânico ou no cognitivo, a manutenção da vida passa pela interação constante e permanente entre organismo e meio. Concebe-se essa interação como fonte de sempre novos desequilíbrios que abrem espaço para novas experiências que, por sua vez, geram novos desenvolvimentos afetivos ou cognitivos. Com isso, são possibilitadas novas aprendizagens, escolares ou não, que concorrem para a sobrevivência em todos os níveis da vida humana.
\end{abstract}

Palavras-chave: Homeostase. Conhecimento. Consciência. Aprendizagem.

\begin{abstract}
The present paper discusses the contributions of both neurobiology and genetic epistemology to the construction of the knowledge and the consciousness. We also discuss how these construction processes relate to the conservation of the homeostasis mechanisms of living organisms. Here, we rely on the works of Antonio Damásio and Jean Piaget in order to understand the links between the organism and the epistemic subject as protagonists of the acts of to stay alive, to acquire knowledge and to be aware. In spite of the framework adopted, either organic or cognitive, to remain alive requires ongoing interaction between living organisms and the environment. We consider that such interaction is the source of every new imbalance, which leads to new experiences, and those generate in turn new emotional and cognitive development. Insofar, the interaction between living organisms with the environment leads towards a learning journey, including more than only scholar knowledge, which contributes to survival in all levels of the human life.
\end{abstract}

Keywords: Homeostasis. Knowledge. Consciousness. Learning.

\section{RESUMEN}

En este trabajo presentamos una discusión acerca de los aportes de la neurobiología y la epistemología genética a los procesos de construcción del conocimiento y de la conciencia. Discutimos, aún, cómo estos procesos se refieren a los mecanismos de conservación de la homeostasis de los organismos. Para tratar de entender las conexiones entre organismo y sujeto epistémico como protagonistas de los actos de seguir con vida, conocer y tomar conciencia, estudiamos obras de António Damásio y Jean Piaget. Sea en el marco orgánico o cognitivo, el mantenimiento de la vida pasa a través de la interacción constante y permanente entre el organismo y el medio ambiente. Diseñamos esta interacción como fuente de siempre nuevos desequilibrios que hacen espacio para nuevas experiencias que, a su vez, generan nuevos desarrollos afectivos o cognitivos. Con esto, se hacen posibles nuevos aprendizajes, escolares o no, que contribuyen por la supervivencia en todos los niveles de la vida humana.

Palabras clave: Homeostasis. Conocimiento. Cconciencia. Aprendizaje.

\footnotetext{
* Mestre em Ecologia pela Universidade Federal do Rio Grande do Sul. Doutoranda em Educação em Ciências pela mesma universidade.E-mail: <pamelazsf@ gmail.com>

**Doutor em Psicologia Escolar e do Desenvolvimento Humano (USP). Professor Titular da área de Psicologia da Educação e docente do Pós-graduação em Educação e em Informática na Educação da UFRGS. E-mail: <fbeckerufrgs@gmail.com>
} 


\section{VIVER É CONHECER}

$\mathrm{O}$ ato de conhecer é, inegavelmente, inerente à condição humana. O homem está sempre buscando adquirir conhecimentos relativamente aos fenômenos naturais, sociais, econômicos na tentativa de desvendar o mundo e a realidade que o cercam. Ao relacionar-se com o outro e com o mundo, estabelece trocas através das quais tem a possibilidade de obter informações sobre os mais diversos temas que o instigam.

Conhece-se porque se vive e se vive como humanos porque se conhece. A capacidade de conhecer e aprender torna-se cada vez mais necessária e essencial nas diferentes interações que, enquanto sujeitos, estabelecese uns com os outros - com o meio em geral e com a sociedade em particular.

Nesse processo, "o que poderia ser mais difícil de conhecer do que conhecer o modo como conhecemos?" (DAMÁSIO, 2000, p. 18). Como se dá a construção do conhecimento pelo sujeito? Como a biologia pode nos ajudar a compreender os processos que engendram a produção de uma consciência que permite a percepção que o organismo tem de si mesmo e daquilo que o cerca e é alvo de seu conhecimento? A tentativa de elucidar essas questões norteará as reflexões aqui apresentadas, apoiadas nas contribuições do estudo neurológico da consciência, especificamente de obras de António Damásio (2000, 2011, 2012), abordadas sob o ponto de vista da Epistemologia Genética de Jean Piaget.

\section{SUJEITO E CONHECIMENTO}

Um dos traços mais característicos da espécie humana é a sua capacidade para aprender e, por meio dela, formar representações adequadas da realidade, o que lhe permite adaptar-se e garantir sua sobrevivência. Diante de uma situação problemática inusitada, o indivíduo humano busca uma saída também nova. Se tiver êxito, ele a anexa a seu repertório de soluções e passa a utilizá-la em situações futuras parecidas. Piaget afirma que o sujeito, ante o fracasso das respostas automáticas, apela para regulações ativas. Em tais casos,

[...] nós o constatamos sempre, o que desencadeia a tomada de consciência é o fato de que as regulações automáticas (por correções parciais, negativas ou positivas, de meios já em atuação) não são mais suficientes e de que é preciso, então, procurar novos meios mediante por uma regulação mais ativa $\mathrm{e}$, em consequência, fonte de escolhas deliberadas, o que supõe a consciência (PIAGET, 1977a, p.198).

Cada um constrói para si o conhecimento, como capacidade, através de suas próprias atividades de busca da compreensão do outro e do ambiente a seu redor. Com isso, traz-se à luz a ideia de que a construção do conhecimento é um processo privado, individual, pessoal de cada sujeito; mas, realizado coletivamente, por interação.

Todos estão em relação com o mundo, por meio da sociedade e da cultura das quais fazem parte; todos são sujeitos de emoções e sentimentos que os afetam e exigem reações, respostas. Todos são sujeitos que buscam reagir, responder, conhecer. Viver requer ações, práticas ou cognitivas. Ser sujeito é agir em múltiplos sentidos. Mas, na extensão do organismo biológico e do indivíduo psicológico, mira-se o sujeito epistêmico.

Piaget define como epistêmico o sujeito que age e, ao apropriar-se da própria ação e de seus mecanismos, constrói conhecimento, constitui sua capacidade cognitiva. O sujeito epistêmico forma-se por um processo radicalmente histórico, tendo como ponto de partida sua organização biológica, geneticamente herdada (BECKER, 2012a). A origem da organização biológica humana remonta a bilhões de anos de história evolutiva que se expressa em milhares de anos de civilização, sintetizada nas organizações sociais e culturais humanas (BECKER, 2012a) recentes e atuais. Destarte, o sujeito é, inegavelmente, também histórico, à medida que sua organização biológica se constitui na interação com as ações próprias da cultura na qual está inserido. O sujeito epistêmico é constantemente influenciado pelo meio social em que vive, mas também influencia esse meio. É, por conseguinte, histórico, social, cultural, político... O sujeito é alvo do meio, mas ele também escolhe o meio. Afirma Piaget (1974):

[...] sobretudo, [a evolução] deixou de ser considerada como triagem automática, e passou-se a concebêla cada vez mais como solidária de regulações até mesmo de escolhas, já que o organismo pode escolher seu entorno em vez de sofrer suas imposições ou até afrontá-las. Ora, a seleção orgânica, solidária de aparatos ou reguladores que apresentam cada uma certa plasticidade e sobretudo uma teleonomia cibernética, está seguramente muito mais perto de um sistema de escolhas que da seleção imposta pelo entorno exterior (p. 46).

O sujeito epistêmico constrói conhecimento como estrutura, competência ou capacidade; secundariamente, mas não menos importante, como conteúdo. Ele está inserido em um meio do qual não pode se dissociar. Sua ação é determinante tanto para sua constituição quanto para a transformação do meio. Não basta ter nascido, ter um corpo e um cérebro para ser sujeito de conhecimento. Suas próprias ações, desenroladas no espaço e no tempo, são instâncias que o constituem o tempo todo. A vida toda. Desse modo, o conhecimento tem início quando o sujeito 
age, assimilando alguma coisa do seu meio físico ou social que, doravante, chamar-se-á de objeto (no sentido epistemológico). Piaget considera objeto tudo aquilo que o sujeito pode assimilar, inclusive tudo aquilo que tematiza e, assim, vira alvo de sua preocupação. O objeto epistemológico pode ser uma pessoa, qualquer objeto físico, uma imagem, sensação, experiência, produção cultural, relações sociais, um conceito, uma teoria. Qualquer coisa que venha a ter sentido, significado e possa ser classificada como outro em relação ao sujeito: inclusive suas percepções, seus conhecimentos, sua consciência quando tematizados.

Como capacidade, o conhecimento não está pronto, não está no genoma do bebê recém-nascido, nem no meio social no qual ele cresce e se desenvolve. Como tal o conhecimento, ou capacidade cognitiva, não pode ser transmitido. Cada indivíduo precisa construílo. O conhecimento como estrutura é construído, o conhecimento como conteúdo é objeto de conquista (BECKER, 2010), de assimilação ou de aprendizagem. Dessa maneira, constrói-se conhecimento estrutura, competência ou capacidade; a assimilação ou aprendizagem do conhecimento conteúdo depende desse processo de construção; por isso, conteúdos podem ser transmitidos e aprendidos no sentido estrito. Conhecer não se reduz nunca a copiar, imitar ou fotografar o real. Conhecer é construir capacidades ou estruturas e, com elas, assimilar conteúdos, o que implica transformá-los em função das capacidades ou estruturas assimiladoras.

Conhecer não consiste, com efeito, em copiar o real, mas em agir sobre ele e transformá-lo de maneira a compreendê-lo em função dos sistemas de transformação aos quais estão ligadas estas ações (PIAGET, 1973, p. 15).

Conhecer é agir sobre os objetos e retirar deles, ou das ações sobre eles, qualidades que lhes são próprias. Mas, de que forma essa ação se dá? Quem age no processo de construção cognitiva? Que mecanismos biológicos estão envolvidos no ato de conhecer?

É fundamental elucidar tais questões relativas à construção do conhecimento. "Os conhecimentos não partem, com efeito, nem do sujeito (...) nem do objeto (...), mas das interações entre sujeito e objeto" (PIAGET, 1973, p. 39-40). É na interação, ou seja, na ação do sujeito sobre o objeto, na resposta do objeto a essa ação, gerando desequilíbrio em seu autor, na modificação que o sujeito realiza em seu âmbito para refazer o equilíbrio perdido e, finalmente, na nova ação sobre o objeto é que se estabelece o processo de construção do conhecimento. Ao modificar o objeto (epistemológico), o sujeito se modifica, transforma a si mesmo, aumentando sua capacidade de agir sobre o objeto.
Tome-se como exemplo, você, leitor deste texto. Ao se deparar com os conceitos e ideias aqui discutidos, alguns talvez percebidos como insólitos ou desconhecidos, instaura-se uma ação; uma ação de sujeito em relação ao texto, objeto de conquista de seu conhecimento. Nesse momento, o texto também retroage sobre você: afetalhe, instiga-lhe, faz-lhe querer dar conta de seu conteúdo até que você consiga compreendê-lo. Sua compreensão e interpretação serão diferentes das de outro leitor, que também se esforçará para dar conta do conteúdo aqui apresentado. Ele construirá seu conhecimento do mesmo modo, agindo e apropriando-se de suas ações, embora faça o caminho à sua maneira. Vale lembrar que nunca é demais insistir, que o sujeito epistêmico é histórico. Sua historicidade imprimirá diferentes leituras ou significados ao objeto a ser conhecido. O processo de construção dependerá necessariamente das ações do sujeito; já os caminhos percorridos e suas respectivas durações, assim como os objetos escolhidos, são históricos, contingentes. No limite, um leitor poderá abandonar o texto porque sente que não tem condições de decifrá-lo, enquanto outro poderá fazê-lo porque o texto não lhe traz novidades.

Para Piaget (1973, p. 71), “(...) a primeira função do conhecimento é ser uma assimilação, no sentido precisamente de uma interação entre o sujeito e o objeto". Serão, então, as múltiplas ações do objeto suficientes para produzir diretamente transformações no sujeito? Absolutamente não. A função do objeto não é essa. Ao contrário, consiste em produzir desequilíbrios no sujeito, em gerar neste a necessidade de reorganizar-se em função da novidade assimilada, da perturbação imposta pelo meio. O que então será responsável por transformar o sujeito? Recorre-se a Piaget (1973, p. 16) para responder a essa questão: “(...) o que transforma o sujeito do conhecimento é a acomodação, a partir de uma assimilação". O objeto chega ao sujeito por meio da ação assimiladora do próprio sujeito. Porém, é necessário que o objeto atinja as organizações internas do sujeito e isso se dá à medida que o desequilíbrio provocado por sua assimilação desafie as estruturas do sujeito a modificar-se. Se for considerado como objeto o conhecimento-conteúdo, este "precisa ser assimilado com tudo o que isso significa de construção mediante inúmeras acomodações em resposta aos desequilíbrios provocados por assimilações anteriores" (PIAGET, 1973, p. 14) até que se atinja uma adaptação satisfatória e o equilíbrio seja novamente restabelecido. Isso se dá por acomodação, que significa reconquista do equilíbrio, mas em nível superior ao equilíbrio anterior; o preço para reconquistar o equilíbrio é o de uma nova construção. Mesmo assim, esse restabelecimento é provisório, pois o sujeito poderá ser de novo perturbado, reiniciando-se todo o processo; porém, agora, num patamar superior ao anterior - equilibração majorante, dirá Piaget (1977b). 
Aprende-se com Piaget que, para compreender o processo de aprendizagem precisa-se entender o processo de desenvolvimento do conhecimento; do conhecimento como capacidade, não apenas como conteúdo. Ao escolher entre miríades de objetos que servirão de estímulo para o jogo de assimilações e acomodações, a ação do sujeito exerce papel determinante. O desenvolvimento não se dá por força do estímulo - o que não significa que ele não tenha importância. Este ocorre por força da ação do sujeito que busca satisfazer suas necessidades - biológicas, psicológicas ou cognitivas. Ação do bebê, da criança, do adolescente, do adulto, do idoso. Por isso, deve-se prestar atenção na ação do sujeito, naquilo que ele faz. Mesmo que se submeta alguém a um determinado estímulo, positivo, negativo ou aversivo, deve-se prestar atenção na ação do sujeito e só secundariamente no estímulo, visto que cada pessoa reage diferentemente a um mesmo estímulo e escolhe os estímulos em função de seus interesses. A ação do sujeito é responsável pelas modificações sofridas por ele. O estímulo ao ser assimilado impõe mudanças, não as causa. A ação causa mudanças, tanto no objeto (assimilação) quanto no sujeito (acomodação).

$\mathrm{O}$ estímulo não pode produzir modificações no sujeito! Porém, o estímulo atua como um sinalizador, ou melhor, como um "desequilibrador". Diante disso, é o próprio sujeito quem restaura o equilíbrio, construindo algo novo, mediante sua ação. Por isso, Piaget afirma algo que pode parecer absurdo à primeira vista: a resposta já está lá no sujeito, antes mesmo do estímulo atingi-lo ou ser assimilado por ele. A capacidade de assimilação, a organização ou a estrutura é que produzem a resposta, não o estímulo; e estas foram construídas previamente ao impacto de determinado estímulo.

Quando o sujeito resolve um problema, provocado por um estímulo, ele constrói algo novo para si. Ele fez, portanto, o desenvolvimento avançar um pequeno degrau e, com isso, ele aumentou sua capacidade de aprender. A importância do estímulo está, pois, em sua função: desequilibrar o sujeito. A condição para isso é que ele seja assimilado; para que o sujeito o assimile deverá significá-lo; ele o faz elegendo um entre os numerosos que estão à disposição. A assimilação é precisamente o ato significador. Não é o estímulo que produz algo novo no sujeito. Tudo o que o estímulo faz é desequilibrar. Mesmo assim, ele desequilibra somente se o sujeito o assimilar. Uma bola de futebol pode desequilibrar uma criança de 2 anos, um adolescente ou um adulto, mas não desequilibra um bebê de 5 meses; porque ele não consegue assimilála. A ação do sujeito não deve se restringir apenas à assimilação; deverá prolongar-se como acomodação (modificar o esquema de assimilação) para produzir transformação na capacidade cognitiva do sujeito. Essa transformação melhora a capacidade de aprendizagem.

\section{A PERSPECTIVA NEUROBIOLÓGICA DE DAMÁSIO}

É interessante destacar que Damásio (2000, 2012) vale-se também do conceito de objeto, tido por ele como qualquer coisa que venha a ser conhecida no processo de consciência ou perturbe a homeostasia. Porém, na abordagem neurobiológica do autor, o objeto agirá sobre o organismo, constituído pela parceria cérebrocorpo, provocando-lhe mudanças. O organismo está constantemente empenhado em relacionar-se com o objeto e este lhe deixa marcas de diferentes maneiras. Emoções, sentimentos, imagens, sons, pessoas, etc. serão constantemente processados pelo sistema nervoso.

Ao nascer, o cérebro humano inicia seu desenvolvimento dotado de impulsos e instintos que incluem não apenas um kit fisiológico para a regulação do metabolismo, mas também dispositivos básicos para fazer face ao conhecimento e ao comportamento social (DAMÁSIO, 2012, p. 125).

Para o autor, a função global do cérebro é estar bem informado sobre o que se passa no restante do corpo; sobre o que se passa em si próprio; e sobre o que se passa no meio no qual se situa o organismo, com vistas a prover mecanismos de sobrevivência adequados entre ele e o ambiente (DAMÁSIO, 2012).

"Se o corpo e o cérebro interagem intensamente entre si, o organismo que eles formam interage de forma não menos intensa com o ambiente que o rodeia" (DAMÁSIO, 2012, p. 97). Perceber o ambiente não é, porém, fazer com que o cérebro receba sinais diretos de determinado estímulo. O organismo altera-se ativamente a fim de encontrar a melhor forma de sobreviver. É desse processo de interação organismo-ambiente que emerge a consciência. "O que poderia ser mais deslumbrante do que perceber que é o fato de termos consciência que torna possíveis e mesmo inevitáveis nossas questões sobre consciência?" (DAMÁSIO, 2000, p. 18). Damásio (2011) define consciência como "[...] um estado mental no qual existe o conhecimento da própria existência e da existência do mundo circundante" (p. 197).

Em seu nível mais simples e mais elementar, a consciência possibilita ao organismo reconhecer um impulso irresistível para permanecer vivo e cultivar o interesse por si mesmo. Já em seu nível mais complexo e elaborado, a consciência ajuda-o a cultivar um interesse também por outras pessoas e aperfeiçoar a arte de viver (DAMÁSIO, 2000). A consciência surge ao longo da evolução biológica para equipar nosso organismo na complexa manutenção de si mesmo, da vida e para perceber a si mesmo como protagonista desse processo, seja organicamente, seja nas interações que estabelece com o meio. 
Nesse contexto, Damásio levanta dois problemas. Primeiro, como o cérebro engendra, no organismo humano, padrões mentais denominados imagens de um objeto? As imagens de um objeto nada mais são do que uma "estrutura construída com os sinais provenientes de cada uma das modalidades sensoriais - visual, auditiva, olfativa, gustatória e sômato-sensitiva" (DAMÁSIO, 2000, p. 402). A palavra imagem não se refere somente a imagem "visual", mas a inumeráveis imagens corporais, e nada tem de estático. O canto do sabiá, o cheiro da chuva, uma dor de dente, uma saudade, um lugar, uma pessoa, um sabor, que constituem o pano de fundo de cada instante mental, são imagens que sinalizam aspectos do estado do próprio corpo.

Assim, o primeiro problema da consciência trata de como se obtém um "filme" no cérebro. Filme esse produzido ao perceber os objetos e convertê-los em imagens, de fora do cérebro em direção a seu interior, e também quando se reconstroem objetos a partir de memórias; nesse caso, de dentro para fora. Esse problema permite conhecer as reações que os objetos causam, as sensações que despertam, a percepção desse fluxo contínuo de imagens, muitas delas reveladas e logicamente inter-relacionadas.

Segundo problema da consciência: como, paralelamente ao engendramento de imagens mentais de um objeto, o cérebro engendra um sentido de self no ato de conhecer? O self emerge como uma percepção que cada organismo tem de si mesmo. A consciência fornece ao organismo um sentido de self capaz de revelar que é o organismo que está agindo, sentindo, pensando... e não outrem. Tal sentido confere ao organismo a existência da sua presença em relação a um objeto: o próprio organismo. É graças a este, que Mafalda, a famosa personagem de Quino, cartunista argentino, é capaz de divagar sobre si mesma (Figura 1):

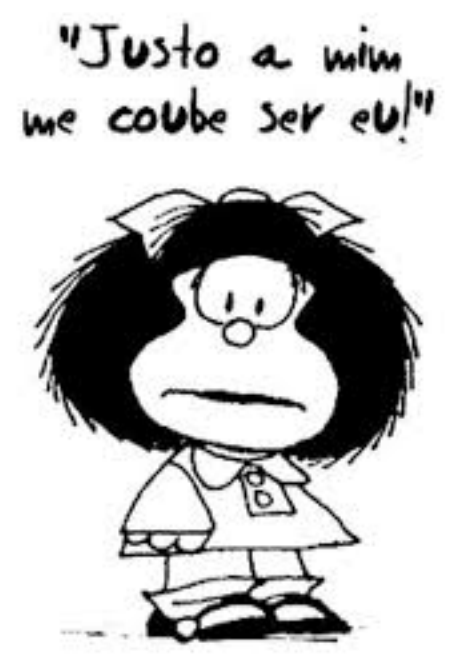

Figura 1. Personagem Mafalda em seus devaneios. ${ }^{1}$
A consciência permitiu ao organismo tornar-se conhecedor de suas próprias dificuldades. [...] Conhecer, em comparação com ser e fazer, foi uma novidade revolucionária (DAMÁSIO, 2011, p. 220).

Tome-se novamente você, leitor, como exemplo para ilustrar tais questões. As palavras que estão sendo usadas para que as ideias cheguem até você são formadas, primeiramente, como imagens de fonemas, códigos, antes de serem implementadas em sua versão escrita. São imagens auditivas, visuais ou sômato-sensitivas. Você lê as palavras, presta atenção naquilo que está contido no texto, atribui significado à leitura e às ideias que lhe vão sendo apresentadas. De modo semelhante, essas palavras impressas que passam diante dos seus olhos são primeiramente processadas por você como imagens verbais através das quais as ideias, que correspondem às palavras que se escreve, podem ser exibidas mentalmente. Porém, isso certamente não descreve tudo o que está acontecendo na sua mente. Esta exibe outras coisas para certificar que é você quem faz isso, e não outra pessoa. Existe a sua presença em relação a um objeto, o texto. Se não fosse assim, como dizer que seus pensamentos, impressões, reações pertencem a você? É o sentido de self que garante quem é o proprietário e protagonista do ato de conhecer.

Todo esse processo implica memória. E esta não é o self, porém a existência do self passa pela memória, implica-a. Mas essa abordagemnão se pretende fazer neste texto ${ }^{2}$.

\section{Piaget e damásio em relação}

Estabelecendo um paralelo com a obra piagetiana, pode-se considerar a consciência como uma produção do sujeito? Há razões para se responder afirmativamente, visto que a consciência também pode ser concebida como fruto da atividade do sujeito, na medida em que este se apropria de suas próprias ações em todos os níveis de sua atividade física e mental. Sendo assim, a consciência existiria a partir da ação do próprio sujeito, sendo um fenômeno inteiramente pessoal e privado, assim como a aprendizagem. Ninguém pode tomar consciência pelo outro, assim como ninguém pode aprender pelo outro. Outra questão, facilmente confundida com esta, é como se aprende. Freire responde, referindo-se ao processo educacional (e o mesmo vale para a aprendizagem):

\footnotetext{
Imagem disponível em <http://flaviohastenreiter.com/2014/03/01/justoa-mim-me-coube-ser-eu/>. Acesso em: 29 dezembro 2014.

2 Recomendam-se: Memória e inteligência [1979], de Piaget; e toda a vasta e renomada obra do neurocientista Ivan Izquierdo, do Centro do Cérebro - PUCRS, a começar com Memória, 2002.
} 
Isto significa:

1. que ninguém educa ninguém;

2. que ninguém tampouco se educa sozinho;

3. que os homens se educam entre si, mediatizados pelo mundo (FREIRE, 1974, p. 18).

Tomar consciência e aprender são processos radicalmente individuais. Como se realizam? Na relação com os outros e com o entorno. Piaget dirá, em interação. Quanto mais qualificada essa interação, tanto mais construtivos serão esses processos.

Um segundo paralelo repousa sobre a noção de organismo, presente em Piaget e Damásio. O organismo é aquele centro de atividade no qual se dão as regulações orgânicas, que, sob o ponto de vista biológico, são responsáveis pela sua manutenção e sobrevivência. Tais regulações concorrem para a manutenção de um equilíbrio dinâmico do sistema, que inclui regulações hormonais, nervosas, químicas, que visam à coordenação de todo o conjunto (PIAGET, 1973). A regulação automática do $\mathrm{pH}$, da temperatura corporal, da concentração de oxigênio no organismo, por exemplo, é essencial para a garantia da vida e para a manutenção do metabolismo.

Destarte, o organismo passa por sucessivas autorregulações a fim de lograr sua homeostase, ou seja, seu estado de equilíbrio. A homeostasia relaciona-se a reações fisiológicas coordenadas e, em grande parte, automáticas, necessárias para manter os níveis internos do organismo estáveis (DAMÁSIO, 2000). Para o autor, a sobrevivência em um meio complexo, o que significa a gestão eficaz da regulagem da vida, depende de executar a ação certa, no momento certo, e isso pode ser feito de maneira muito mais eficiente se houver intencionalmente a antevisão e a manipulação de imagens na mente, aliadas a um planejamento ótimo. "A consciência permitiu a conexão de dois aspectos díspares do processo - a regulagem interior da vida e a produção de imagens" (DAMÁSIO, 2000, p. 44). A partir disso, pergunta-se se é possível se conceber a consciência como um fenômeno que surge para garantir a homeostase e, consequentemente, para a manutenção da vida nos níveis mais avançados do desenvolvimento cognitivo humano? Há evidências para admitir isso. A consciência torna possível que qualquer objeto seja conhecido pelo organismo e, com isso, aumenta a capacidade do mesmo para reagir de maneira adaptativa, atento às suas necessidades (DAMÁSIO, 2000).

Piaget (1973, p. 38) reconhece a importância da manutenção de um equilíbrio dinâmico a ponto de asseverar que "a vida é essencialmente autorregulação". Essa hipótese-diretriz faz com que o autor se debruce sobre a relação entre as regulações orgânicas e as regulações cognitivas, considerando esas extensões daquelas. É um mesmo mecanismo autorregulador, biológico ou orgânico, que se transforma em um mecanismo autorregulador cognitivo, pelo desenrolar do processo adaptativo: o sujeito também persegue um constante equilíbrio nas relações com o meio em que está inserido. Este o instiga, provoca perturbações, desequilibra, ou seja, desafia o sujeito a sucessivas assimilações. É necessário, então, que o sujeito refaça suas estruturas assimiladoras em função dessa provocação, desse desequilíbrio, desses desafios. Nesse movimento, o sujeito se refaz por acomodação, pela qual transforma seus esquemas assimiladores, restabelecendo o equilíbrio perdido ao assimilar com melhor capacidade e construindo novos patamares de equilíbrio. A assimilação consiste em trazer alguma coisa de fora para dentro do sujeito. Assim, o sujeito seleciona aquilo que irá assimilar - toda assimilação é escolha! Não se assimila qualquer coisa, não é qualquer estímulo que mobiliza o organismo, o indivíduo, o sujeito. Se essa assimilação se prolongar em acomodação, será sinal claro de que se trata de aprendizagem significativa, pois se desenrola no plano do desenvolvimento.

É interessante se pensar que "qualquer que seja a questão que possamos levantar sobre quem somos e por que somos como somos, uma coisa é certa: somos organismos vivos, complexos, com um corpo que contém um cérebro" (DAMÁSIO, 2012, p. 93); que ambos, corpo e cérebro, interagem entre si e com o meio e estão insistentemente empenhados em dar conta de todo o necessário para a garantia da sobrevivência. $\mathrm{Na}$ perspectiva da neurobiologia, a acomodação piagetiana pode ser compreendida como conexões neuronais que o cérebro faz para conseguir superar os desafios que a luta pela sobrevivência vai impondo e que o sujeito até então não conseguia responder; e conserva o que realizou. Logo, "os cérebros permitem que o ímpeto da vida seja regulado com grande eficácia e, em certo momento da evolução, conscientemente" (DAMÁSIO, 2000, p. 182). A cada momento, o cérebro reconstrói o sentido de self, sendo este, desde seu surgimento, um estado do organismo.

Pode-se perguntar: como é que se começa a ser consciente? "Especificamente, como é que chegamos a ter um sentido de self no ato de conhecer?" (DAMÁSIO, 2000, p. 218). O nascimento da consciência ampara-se na interação entre organismo e objeto: "Tornamo-nos conscientes quando internamente nosso organismo constrói e exibe um tipo específico de conhecimento sem palavras - o conhecimento de que nosso organismo foi mudado por um objeto" (DAMÁSIO, 2000, p. 218). A partir do surgimento da consciência, surge o sentido de self, que atesta que somos conscientes.

Damásio distingue basicamente três tipos de self. O primeiro, o proto-self, consiste em "padrões neurais que representam o estado do organismo, a cada momento, em vários níveis do cérebro" (DAMÁSIO, 2000, p. 225). O proto-self está empenhado no processo de regulação do organismo. 
Não se é consciente do proto-self. Este não tem percepção, tampouco tem capacidade de produzir conhecimento. Assim sendo, o seu papel estaria restrito à manutenção da homeostase do organismo? Está-se subestimando o seu potencial e importância ao se restringir sua função a isso, por mais essencial que seja.

Ele participa do processo de conhecimento, esperando pacientemente que um cérebro muito generoso explique o que se passa respondendo a perguntas nunca formuladas: Quem faz? Quem sabe? (DAMÁSIO, 2000, p. 201).

Quando surge a resposta à primeira pergunta, emerge o sentido de self, que é um conhecedor que sabe. Destarte, na medida em que o cérebro forma imagens de um objeto e essas imagens afetam o estado do organismo, modificando o proto-self, o segundo tipo de self passa a existir: o self central.

O self central é o "protagonista transitório da consciência" (DAMÁSIO, 2000, p. 226), gerado a partir de qualquer objeto que acione a consciência central. Esta nos fornece um sentido de self concernente a um momento, agora, e a um lugar, aqui. Assim, o self central é uma entidade transitória, criada incessantemente para cada objeto.

Todavia, em organismos complexos como o nosso, alguns fatos podem ser registrados na memória e relacionados a outras informações relativas ao passado ou ao futuro antevisto, conduzindo ao desenvolvimento da memória autobiográfica: um agregado de registros sobre quem temos sido e sobre o que planejamos ser no futuro. Eis o terceiro tipo de self: "Quando certos registros pessoais se explicitam em imagens reconstruídas, em maior ou menor número, conforme o necessário, eles se tornam o self autobiográfico" (DAMÁSIO, 2000, p. 224). Esteé progressivamente tributário daquilo que Piaget chama de tomada de consciência. A vida humana, individual e coletiva, é pautada pelo self autobiográfico.

\section{O CONHECIMENTO E A CONSCIÊNCIA NO ATO DE APRENDER}

Parafraseando Piaget (1977c), para apresentar uma noção adequada de aprendizagem, precisa-se compreender inicialmente como o sujeito constrói e inventa conhecimento e não somente como ele copia e reproduz aquilo que lhe é apresentado. Esclarece-se a partir de Piaget que o conhecimento tem início e se desenvolve somente quando o sujeito age e organiza ou coordena suas ações. Para ele, o conhecimento surge como prolongamento da ação do sujeito ou, melhor, das coordenações das ações; é sempre resultado de uma ação de segundo grau, uma ação sobre as ações primeiras, as ações que buscavam êxito. $\mathrm{O}$ conhecimento busca a verdade, não o êxito. A epistemologia genética situa na ação o núcleo a partir do qual se originam as sucessivas estruturas cognitivas (BECKER, 2012b). Aprende-se algo novo e diferente porque se age para essa conquista. Não se aprende porque se ensina, embora o ensino possa contribuir para a aprendizagem. "Ensinar não é transferir conhecimento, mas sim criar as possibilidades para a sua própria produção ou a sua construção" (FREIRE, 1996, p. 24). Se for tomada como referência a escola, lugar reconhecidamente tido como espaço de aprendizagem em função do ensino, que implicações isso poderá trazer?

No mínimo, a implicação mais significativa é a de que o ensino não pode ser visto como a fonte de toda aprendizagem, até porque a maior parte do que se aprende na vida faz-se fora da escola. Já se sabe que a fonte de aprendizagem está no sujeito, na sua ação. É preciso que se compreenda o processo de construção do conhecimento como condição prévia a qualquer aprendizagem. O conhecimento consiste, essencialmente, não apenas em adquirir e acumular informações (conteúdos), mas, sobretudo, em organizá-las no sentido da solução de problemas (PIAGET, 1973). O que se faz construindo estruturas capazes de operar; sem isso, as informações ou os conteúdos ficariam inócuos ou inoperantes.

Falar de construção de conhecimento é falar em construtivismo. Nessa visão epistemológica, "constrói-se não apenas conteúdos, mas sobretudo formas, estruturas ou capacidades" (BECKER, 2010, p. 15) - os verdadeiros a priori de todo conhecimento. Isso significa que o sujeito, ao agir sobre o meio, assimilando-o, tem seu equilíbrio cognitivo desestabilizado. A dinâmica autorreguladora do organismo exige que se refaça o equilíbrio perdido em todos os níveis, incluindo o cognitivo, visto que as funções cognitivas são extensões das funções orgânicas; porém, com características próprias que não se reduzem às características das funções orgânicas. No que concerne ao conhecimento, não é diferente. Esse equilíbrio se refaz momentaneamente, por acomodação, que consiste em:

\footnotetext{
[...] uma transformação, realizada pelo sujeito, de suas formas de agir, de assimilar, de tal modo que, ao enfrentar novamente problemas iguais, ou parecidos, estará mais instrumentalizado para dar respostas mais adequadas em relação àquelas que dera antes (BECKER, 2010, p. 16).
}

Por esse motivo, a teoria piagetiana propõe que a construção do conhecimento está fundada na interação, que expressa o dinamismo da complementaridade da assimilação e da acomodação. Interação sujeito-objeto, na qual o sujeito assimila a realidade, e esta, por sua vez, impõe a ele, pela própria assimilação, desafios que o "obrigam" a realizar modificações em seus esquemas ou estruturas assimiladoras, na organização das ações (BECKER, 
2012b). De acordo com o autor, assim como a assimilação produz transformações no mundo do objeto, a acomodação produz transformações no mundo do sujeito. Note-se que ambas as transformações são obra do próprio sujeito.

É pena que a compreensão do construtivismo na escola encontre-se reduzida à compreensão da assimilação de conteúdos possibilitados por "estágios" (estádios) de conhecimento fixos, mais ou menos iguais para todo mundo. O construtivismo foi reduzido, por um lado, a um inatismo que Piaget (1977c) sempre criticou; e, por outro, a um empirismo, também alvo de críticas contundentes desse autor. "Acreditamos que a verdade está entre estes dois extremos, isto é, num construtivismo que exprime a maneira pela qual novas estruturas são constantemente elaboradas” (p. 111); “[...] em direção a um construtivismo, que é outra epistemologia, aliás, muito mais próxima das atuais linhas biológicas, que salientam a necessidade das autorregulações construtivas" (p. 113). Não raro, verifica-se na escola um ensino que prioriza transmissão $\mathrm{e}$ repetição de informações, tendo como recursos principais o livro didático e sua transcrição no quadro. No entanto, se o ensino tradicional tem por objetivo fazer que se repita corretamente o que corretamente foi exposto, as máquinas de ensinar, propostas por Skinner, poderão preencher adequadamente essas condições (PIAGET, 1976). Hoje, Piaget diria o mesmo para o uso de computadores, celulares, tablets, iPhones, etc., cuja presença nas escolas em quase nada tem modificado esse panorama epistemológico. Não são poucos os casos em que se tem reforçado a concepção apriorista, inatista, pedagogicamente espontaneísta segundo a qual a mera presença da tecnologia nas salas de aula garantiria a aprendizagem esperada.

$\mathrm{Na}$ perspectiva construtivista, o professor deve compreender que sua ação é a de mediador das relações de pesquisa coletiva entre os alunos, valorizando a vida social (troca entre os alunos, conflitos sociocognitivos, pesquisa coletiva), visando à socialização progressiva por meio do trabalho em equipe (KEBACH, 2010). O processo de aprendizagem situa-se no prolongamento do processo de (re)construção de estruturas cognitivas - o desenvolvimento; essas estruturas constituem a condição da assimilação de qualquer conteúdo (BECKER, 2012b). A construção ou a produção do conhecimento implica o exercício da curiosidade, da capacidade crítica de "tomar distância" do objeto, de observá-lo, de delimitá-lo, de "cercar" o objeto ou fazer sua aproximação metódica, da capacidade de comparar, perguntar, intervir, dizer, ousar o novo, buscar, conscientizar-se, pensar, dialogar (FREIRE, 1996); e não apenas copiar e repetir.

É preciso se pensar o problema do ensino considerando, por um lado, os efeitos cada vez mais graves da compartimentação dos saberes e da preocupante incapacidade de articulá-los entre si; por outro lado, considerando igualmente que a aptidão para contextualizar e integrar é uma qualidade fundamental da mente humana, esta precisa ser desafiada para evitar sua atrofia (MORIN, 2002). O propósito do professor não deve ser mais o de levar o aluno a adquirir informações isoladas e desconexas, mas sim de ajudá-lo a mobilizar esquemas cognitivos que o permitam elaborar questões e responder a estas, resolver desafios, articular informações, sintetizar conhecimentos e mobilizá-los nas situações do cotidiano em que eles forem requeridos. Não se deve isolar uma palavra, uma informação; é necessário ligá-la a um contexto e mobilizar o saber e a cultura de que se dispõe para chegar a um conhecimento oportuno e apropriado da mesma (MORIN, 2003).

Faz-se necessário lembrar também que o sujeito epistêmico é histórico e social. Compreende-se que o processo de construção das estruturas cognitivas é radicalmente individual, porém realizado coletivamente. As diferenças entre os vários indivíduos devem-se, simultaneamente, tanto às características do meio físico e social no qual se encontram inseridos quanto à qualidade das suas estruturas prévias (BECKER, 2012b). É por esse motivo que se encontram diferenças marcantes entre alunos que pertencem a um meio relativamente homogêneo e também semelhanças entre alunos de meios heterogêneos.

A evolução do self central faz surgir o self autobiográfico, específico dos indivíduos humanos. É o self historicizado, da consciência histórica. Ele depende de

[...] lembranças sistematizadas de situações das quais a consciência participou no processo de conhecer as características mais invariáveis da vida de um organismo: quem o gerou, onde, quando, seus gostos e aversões, o modo como habitualmente se reage a um problema ou conflito, seu nome, seus gostos, sua idade, seus parentescos, o lugar em que nasceu e vive, etc. (DAMÁSIO, 2000, p. 35).

Ao longo do tempo evolutivo, o surgimento do self autobiográfico possibilitou que se adquirisse conhecimento sobre aspectos cada vez mais complexos do meio físico e social do organismo, "assim como sobre o lugar e o campo de ação potencial do organismo em um novo universo complicado" (DAMÁSIO, 2000, p. 255).

Grosso modo, o self autobiográfico permite o registro das interações estabelecidas entre organismo e meio, interação esta que é condição do desenvolvimento cognitivo e, por extensão, da aprendizagem. Pode-se, então, na perspectiva neurobiológica, dizer que o self autobiográfico é uma condição necessária para que se possa ter consciência daquilo que se aprende? Em parte, sim. Porém, outro elemento é necessário à consciência para que o organismo perceba a si mesmo enquanto sujeito histórico e igualmente perceba aquilo que o cerca e é alvo de seu conhecimento: a memória operacional. 
Esta é "precisamente a capacidade de reter imagens na mente por um tempo suficiente para que elas possam ser manipuladas de maneira inteligente" (DAMÁSIO, 2000 , p. 257). Ou seja, a condição para que numerosas representações possam ser mantidas na mente, por um longo período de tempo.

Graças à memória operacional, estabelecem-se memórias indispensáveis para o planejamento, resolução de problemas, criatividade e aprendizagem. Tais habilidades são, definitivamente, indispensáveis ao desenvolvimento de comportamentos e estratégias de sobrevivência e adaptação. Por meio de um self autobiográfico, que dá identidade, e estruturas cognitivas, que possibilitam a assimilação cognitiva do meio, podem-se realizar novas aprendizagens, e cada um pode transformar a si mesmo e também a realidade na qual está inserido. Afinal,

[...] nossa presença no mundo não é a de quem a ele apenas se adapta, mas a de quem nele se insere; o preço a pagar por essa inserção é transformá-lo. É a posição de quem luta para não ser apenas objeto, mas também sujeito da história (FREIRE, 1996, p. 53).

\section{CONSIDERAÇõES FINAIS}

Os organismos vivos são produtos constantes da interação organismo-ambiente. Ao mesmo tempo em que se caracterizam por autonomia biológica, dependem do meio externo para sua sobrevivência. Resistir ao meio, permanecer vivo e garantir a sobrevivência passa por uma constante e fina interação entre organismo e meio. Nesse processo, cada organismo possui uma organização interna que lhe permite ajustar-se aos desequilíbrios produzidos pelo meio e perseverar ou fenecer. A manutenção biológica do organismo conduz, no processo evolutivo, à emergência do conhecimento, da consciência e também da delicada rede de relações que perpassa sua conservação e seu processo homeostático.

Seja na perspectiva orgânica ou na cognitiva, a estabilidade almejada pelo organismo e pelo sujeito decorre dos processos de autorregulação ou homeostasia. A consciência, no âmbito orgânico, permite que qualquer objeto seja conhecido e, com isso, aumenta a capacidade do organismo de responder de maneira adaptativa, atendendo às suas necessidadesEsta está vinculada à sobrevivência do organismo que, para manter-se vivo, age incessantemente sobre os objetos físicos, sobre os objetos da cultura e do saber, modificando-os e, pelo processo de interação, modifica-se, desafiado por esse entorno físico ou social. Torna-se, assim, sujeito da construção de suas capacidades cognitivas, que também o instrumentalizam para constituirse sujeito autônomo capaz de exercer autoria em suas aprendizagens pela vida afora. $\mathrm{O}$ processo educacional é, também, uma extensão do processo de autorregulação, de homeostasia, enquanto prolonga esses processos, no plano cognitivo, como desenvolvimento, construção de conhecimento, tomada de consciência, consciência central e consciência autobiográfica; são essas capacidades que possibilitam todo tipo de aprendizagem significativa.

\section{REFERÊNCIAS}

BECKER, Fernando. Ensino e pesquisa: qual a relação? In: BECKER, Fernando; MARQUES, Tania Beatriz Iwasko (Org.). Ser professor é ser pesquisador. Porto Alegre: Mediação, 2010, p. 11-20.

BECKER, Fernando. A epistemologia do professor: o cotidiano da escola. Petrópolis: Vozes, 2012a.

BECKER, Fernando. Educação e construção do conhecimento. Porto Alegre: Penso, 2012b.

DAMASIO, António. O mistério da consciência. São Paulo: Companhia das Letras, 2000.

DAMÁSIO, António. E o cérebro criou o homem. São Paulo: Companhia das Letras, 2011.

DAMÁSIO, António. O erro de Descartes: emoção, razão e o cérebro humano. São Paulo: Companhia das Letras, 2012.

FREIRE, Paulo. Uma educação para a liberdade. Porto: Dinalivro, 1974.

FREIRE, Paulo. Pedagogia da autonomia: saberes necessários à prática educativa. São Paulo: Paz e Terra, 1996.

KEBACH, Patrícia Fernanda Carmen. O professor construtivista: um pesquisador em ação. In: BECKER, Fernando; MARQUES, Tania Beatriz Iwaszko (org.). Ser professor é ser pesquisador. Porto Alegre: Mediação, 2010. p. 43-54.

MORIN, Edgar. A cabeça-bem-feita: repensar a reforma, reformar o pensamento. Rio de Janeiro: Bertrand Brasil, 2002.

MORIN, Edgar. Da necessidade de um pensamento complexo. In: MARTINS, Francisco Menezes; SILVA, Juremir Machado. Para navegar no século XXI. Porto Alegre: Sulina/EDIPUCRS, 2003, p. 13-36.

PIAGET, Jean. Biologia e conhecimento: ensaio sobre as relações orgânicas e os processos cognitivos. Petrópolis: Vozes, 1973.

PIAGET, Jean. Adaptation vitale et psychologie de l'intelligence: sélection organique et phénocopie. Paris: Hermann, 1974.

PIAGET, Jean. [1969] Psicologia e pedagogia. Rio de Janeiro: Forense, 1976.

PIAGET, Jean. A tomada de consciência. São Paulo: EDUSP/ Melhoramentos, 1977a.

PIAGET, Jean. O desenvolvimento do pensamento: equilibração das estruturas cognitivas. Lisboa: Dom Quixote, 1977b.

PIAGET, Jean. A teoria de Piaget. In: CARMICHAEL, Leonard. Manual de psicologia da criança. Desenvolvimento cognitivo I. São Paulo: EPU/EDUSP, 1977c, p. 70115.

PIAGET, Jean. Memória e inteligência. Brasília: Artenova, 1979.

Submetido em: 11/05/2015

Aprovado em: 24/11/2015 